\title{
Retraction: Episodic memory: a comparative approach
}

\section{Frontiers in Psychiatry Editorial Office*}

${ }^{*}$ Correspondence: psychiatry.editorial.office@frontiersin.org

Approved by:

Ekrem Dere, University Pierre and Marie Curie Paris, France

\section{A retraction of the Review Article:}

Episodic memory: a comparative approach

by Martin-Ordas G and Call J (2013) Front. Behav. Neurosci. 7:63. doi:10.3389/fnbeh. 2013.00063

The corresponding author (Gema MartinOrdas) and the journal wish to retract the 11 June 2013 article cited above.

Based on information discovered after publication and reported to the journal in October 2013, this article was found to contain substantial sections that were taken verbatim without quotation and citation. The corresponding author, who was entirely responsible for the unintentional inclusion of this material, agrees with retraction of the article in its entirety and apologizes to the reviewers, editors, and readers of Frontiers in Behavioral Neuroscience for any adverse consequences that may have resulted from the article's publication.

Received: 13 November 2013; accepted: 13 November 2013; published online: 03 December 2013.
Citation: Frontiers in Psychiatry Editorial Office (2013) Retraction: Episodic memory: a comparative approach. Front. Behav. Neurosci. 7:184. doi:10.3389/fnbeh.2013. 00184

This article was submitted to the journal Frontiers in Behavioral Neuroscience.

Copyright (C) 2013 Frontiers in Psychiatry Editorial Office. This is an open-access article distributed under the terms of the Creative Commons Attribution License (CC BY). The use, distribution or reproduction in other forums is permitted, provided the original author(s) or licensor are credited and that the original publication in this journal is cited, in accordance with accepted academic practice. No use, distribution or reproduction is permitted which does not comply with these terms. 